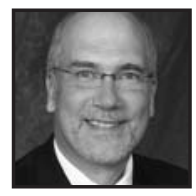

\title{
In Search of Our Students' Voices: The Student Focus Day Story
}

\author{
J. Kenneth Robertson, New Frontiers School Board
}

\begin{abstract}
Much of the literature on "student engagement" focuses on "motivating students to learn" (Voke, 2002), but what of our students' voices in the context of board-wide planning for their success? This is the story of the New Frontiers School Board's Student Focus Day, an initiative aimed at opening the planning process to the voices of our students by inspiring them to engage in open conversation, share in the leadership, and take responsibility for enacting the changes they envision.
\end{abstract}

uch of the literature on "student engagement" and "student voice" focuses on "motivating students to learn" (Voke, 2002), and speaks to students'"psychological investment in learning" (Newman, 1992, p. 2). These writings are often linked to the notion of the classroom as a "professional learning community" as articulated in the work of Richard DuFour $(1998,2004)$, and centers on preparing teachers to give their students an active role in creating the learning and teaching context.

But what of our students' voice in the context of the school board-wide and school-wide strategic planning for "their" success that many North American jurisdictions now mandate? The "Student Focus Day Story" is one that shares how the New Frontiers School Board' (NFSB) attempted to bring its "students' voice" into the planning process. 
Since July 1, 2003, the Province of Quebec in Canada has mandated the creation of School Board Strategic Plans, as well as school and adult center Success Plans. The purpose of these plans is to map out priorities for school boards, schools, and adult learning centres in terms of outcomes, strategies, and indicators of success. In a typically top-down approach, the Government of Quebec sets priorities based on data collected from student results on provincial exams and achievement tests and influence from public expectations of the education system. These are passed down to school boards, which in turn are expected to establish priorities for schools and centres.

Early in the initial planning process, the NFSB decided to take a different approach. Rather than focusing on the provincial priorities, the School Board decided to base its plan on its schools' and centres' priorities. Three themes emerged to form the foundation for the School Board Strategic Plan for Success (SBSPS): enhancing student learning, ensuring students' social/emotional development, and creating an effective learning environment. Provincial priorities were then linked to those of the schools and centres in the context of the SBSPS to satisfy the government requirements. The hope was that this "grassroots approach" would focus the School Board resources to ensure that they serve our schools and centres.

In the second year of implementation of the SBSPS, as the Director General ${ }^{2}$ of NFSB, I was reminded of the importance of our students' voice. Through professional conversation ${ }^{3}$ with a colleague from McGill University who was researching "student engagement,"I was asked if our students had been provided with an opportunity to influence the development of the School Board's plans. Without hesitation I indicated that the students' voice was channelled through the Governing Boards' 4 input into the development of the School Board's priorities. Upon reflection I realized that this was but a faint echo of the students' true voice.

The challenge was to provide an opportunity for students across the School Board to give voice to their feelings, concerns, and suggestions for improving the quality of learning experiences provided by our schools and centres. After discussing a number of possibilities with colleagues and student leaders, we decided that the School Board could give our students the opportunity to influence board-wide planning through a Student Focus Day (SFD), a day dedicated to listening to our students.

The School Board's four secondary Vice-Principals 5 provided the leadership for the day in recognition of their special connection with many of the secondary students who find the school experience challenging or prohibitive. As well, it was felt 
that the Vice-Principals and the students from the elementary feeder schools would benefit from this early opportunity to engage in the dynamic exchange the day promised to provide.

Student teachers who were in their final practicum in several of the NFSB schools were invited to provide the leadership for the small group activities. This was an opportunity to emphasize the importance of student voice in the planning process for a group of future educational leaders.

Most importantly, in recognition of the leadership already provided by our students in our two large high schools, the Student Leadership Team from each school was asked to animate large group "icebreaker activities" throughout the day. The student leaders highlighted for the other students the importance of giving voice to their questions, concerns, hopes, and dreams. This was to become one of the common threads woven into future SFD experiences.

From the beginning, it was clear that it would be important to involve students with different "school" experiences. Students from each school or program offered by the School Board were asked to participate in the day: elementary, middle school ${ }^{6}$, senior secondary, alternative programs, and adult education. Knowing that those selected to participate would greatly influence the tone of the students' voice, schools and centres were asked to select students to participate who demonstrated a balance between those who:

- perform well in the context of the school structure, and those who find living within the school structure challenging;

- enjoy their school experience, and those frustrated by their school experience; and

- provide formal leadership, and those who provide informal leadership.

For example, many of the School Board's secondary alternative students and adult students have opted for these programs because of their frustration with the standard secondary program offered in our high schools. Therefore, it was important to draw on their experiences to determine how they were affected and how things might be done differently in the future.

To ensure that the students understood that this was a special day and that something "different" was going to happen, it was decided that the event should be held at a community venue away from the daily activities of the schools and centres. 
The buses arrived and the energy and enthusiasm with which the students were received by the leadership team immediately signaled that something special was about to happen.

I welcomed the students, emphasizing that this was a first-time event, and that nowhere else in Quebec had students been asked on a board-wide level to contribute to the planning process. I explained that we had brought them together to help us understand how students and educators could collaboratively make our schools and centres more responsive to their learning needs. Immediately the student leaders took over, raising the level of excitement with rousing cheers and series of lively activities that encouraged interaction amongst the students. Small groups combining students of similar levels but different schools and centres were then formed, and the sharing began.

The first main activity of the day was a "Think, Pair, Share" that provided each group with an opportunity to reflect on the three following sets of questions:

- What helps you learn? How do you learn? Think of the strategies and processes that help you learn best. These can include things you do or need in class, the type of teaching or learning styles that work best for you. What else helps you to be successful in school?

- What strategies do you use to be successful? What else can you do when you have difficulty in school?

- What can other people do to help you? Think of the role that these people can play: teachers, principals, school board, peers, professionals (psychologists, social workers, pastoral animators, etc).

Students shared through conversation and wrote their ideas on coloured Post-it ${ }^{\circledR}$ notes, each colour representing a set of questions that were grouped on different sections of the wall. The sheer volume of the visual representation of the students' thoughts, reflections, and ideas showed that the students had a tremendous amount to say. The first activity ended in a plenary session with representatives from each group sharing some of the key notions that had emerged from the paired and small group conversations. Everyone was amazed by how clearly and articulately the students expressed their wants, needs, and desires.

The energy the students had built up over the morning spilled into the lunch break, where the high school students spontaneously began to organize games and activities for the younger students. 
After lunch the student leadership team did a quick activity to bring the group back together. Then in their small groups, the students were asked to review the feedback they had collected during the morning activity, and formulate specific recommendations based on the three themes in the School Board's strategic plan. The students set to work and within a relatively short period of time they formulated a large number of specific recommendations.

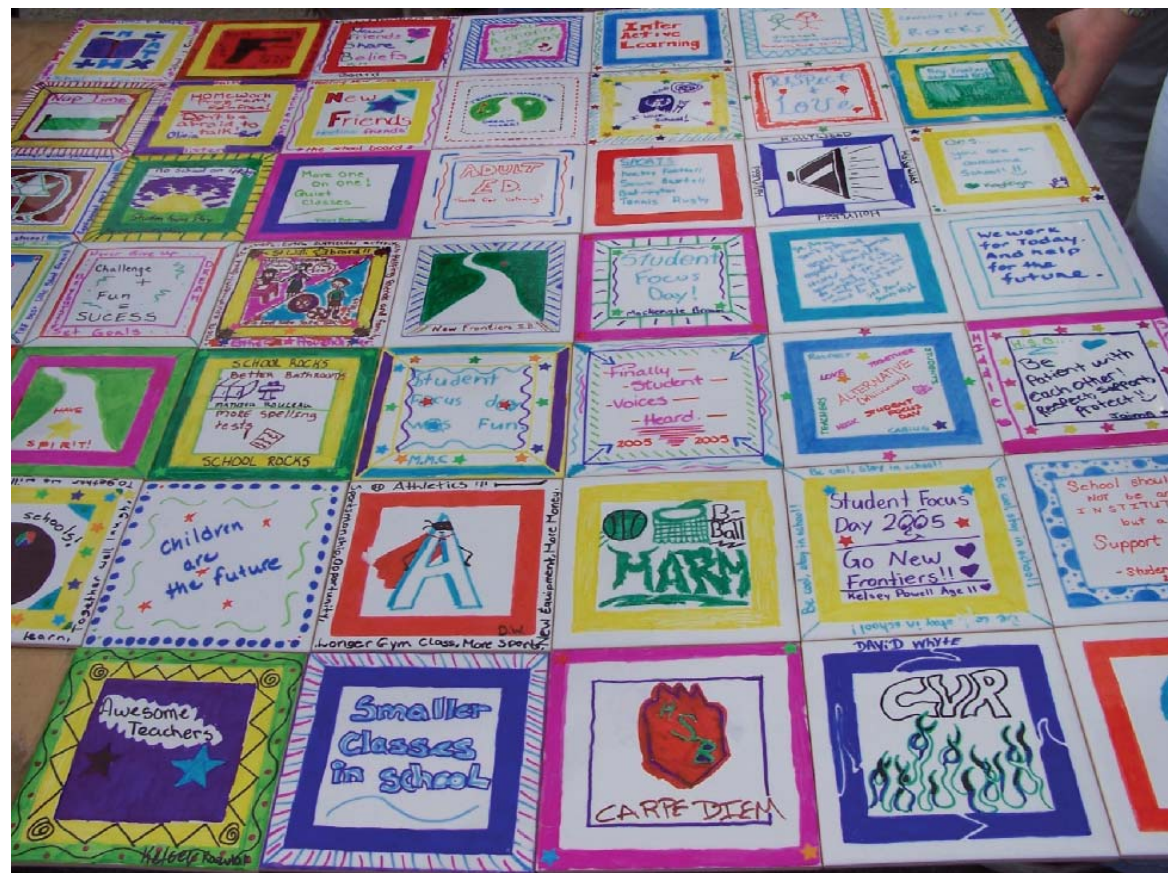

Fig. 1:Visual memory

Everyone felt strongly that it was important to create a "Visual Memory" of the day, and so a collective piece of art was created that memorialized the day. Each student was given a plain, white ceramic tile on which to express their feelings about the day. As the students completed their artwork, the tiles were assembled into a mosaic that is mounted at the School Board office as a reminder that it is essential to ensure that our Students' Voice is woven into every aspect of their education.

The day ended with one final student-led activity that culminated in laughter and hugs. Everyone left with a feeling that this first Student Focus Day would most certainly not be the last. 


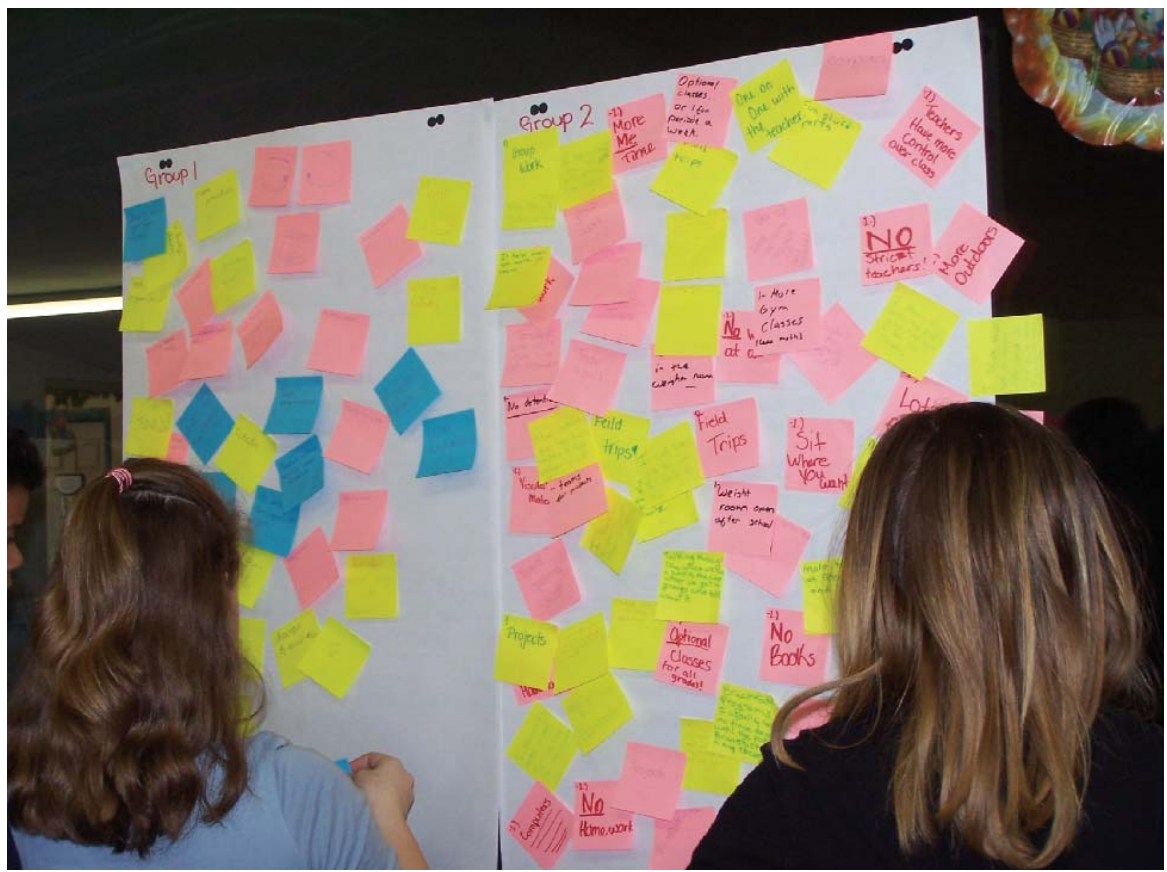

Fig. 2: Student feedback

It is important to note the following when considering the students' feedback. Although representative of our diverse student population, the sample was still relatively small and the positive synergy of the day may have influenced student responses. While we have tried to be true to the students' voices, it is important to note that the summary of the student feedback that follows below is how the organizers interpreted the large amount of qualitative data collected during the activities. Finally, while each summary of the student feedback has been aligned with a specific School Board priority, the respective summaries often bridge all three priorities.

\section{Learning:}

Students voiced, in a variety of ways, the following messages about their learning needs:

- Teachers are the most important influence on our students' learning experience. Students want teachers who are "patient, interesting, fun, and caring."

- Students want to be actively engaged in their learning; they want to be involved in the planning and animation of activities. They link motivation to being part of goal setting, even "planning the day with the teacher." 
- Fifteen elementary students expressed the desire for activities that are "hands-on and visual"; "seeing what we are learning" is key to their success. Twenty-two others called for "projects, group work, and discussion." Middle school and high school students added to these by calling for "energetic activities" and "real-life experience learning." One student went as far as to state directly, "Stop the lectures!" Clearly, they intuitively embrace the constructivist approach?.

\section{Practical comments}

- At the high school level, students expressed the need to review the semester system, the length of periods, and the use of double periods.

- Students at all levels called for more "field trips," emphasizing the importance of experiential learning.

- Throughout the activities, students repeatedly returned to the challenges of homework, suggesting the need for "longer days" to do the homework at school, study halls, and time in class where they could seek the assistance of their teachers and peers.

\section{Emergent notions about social/emotional development:}

- Students crave the synergy created by engaging others intellectually and socially. They need access to teachers, friends, peers, family, and others. (Interestingly, the students reached beyond the traditional contacts and supports and talked about the need to engage: aides, technicians, librarians, security guards, volunteers, custodians, nurses, counselors, vice-principals, principals, community members, and tutors, as summarized by one student, "friendly people.")

- Students have to learn to be their own advocates and actively seek help. Schools and centres have to assist our students by: showing them how to advocate effectively, by encouraging them to seek help, ensuring help is available when needed, developing specific strategies and mechanisms to provide help (e.g., Mediation Stations), and by ensuring that everyone supports the creation of a helping culture.

\section{The practical comments related to this priority}

- Students called for opportunities to "get to know our peers better," the opening of possibilities can be created by "class discussions about us." 
- Students feel the need for more direct contact with their teachers, more one-on-one. This was expressed in two different ways: calls for smaller class sizes, and the suggestion that there be "two teachers in a classroom." This speaks to the benefits of team-teaching or having resource teachers work directly with the classroom teachers.

\section{Environmental themes}

- There was a clear expression of the need for a student-friendly learning environment. Students want to be engaged in creating classrooms that, while being disciplined, orderly, clean, and quiet, allow for music, gum chewing, more colour, fresh air, and water. In essence, they are looking for classrooms, schools, and centres that they can call their own.

- Students want to be supported not only in the ways adults want to support them, but also in the ways they feel they need to be supported. For example, they want help in "figuring out (their) weaknesses," learning to "focus on (their) work," learning how to "quiz (themselves)," and even "finding tricks, such as, guess and check."

- While it might be tempting to place the use of technology under "learning," in fact the students made surprising little direct reference to the need for technology in their learning. Rather, the students often referred to the use of technology more as an integral and necessary part of their environment, an ever-present tool or support to which they should have ready access, as three students simply noted, "use the Internet."

\section{Practical comment (articulated by many of the students)}

- Create "quiet space" where students can study, read, and reflect. 


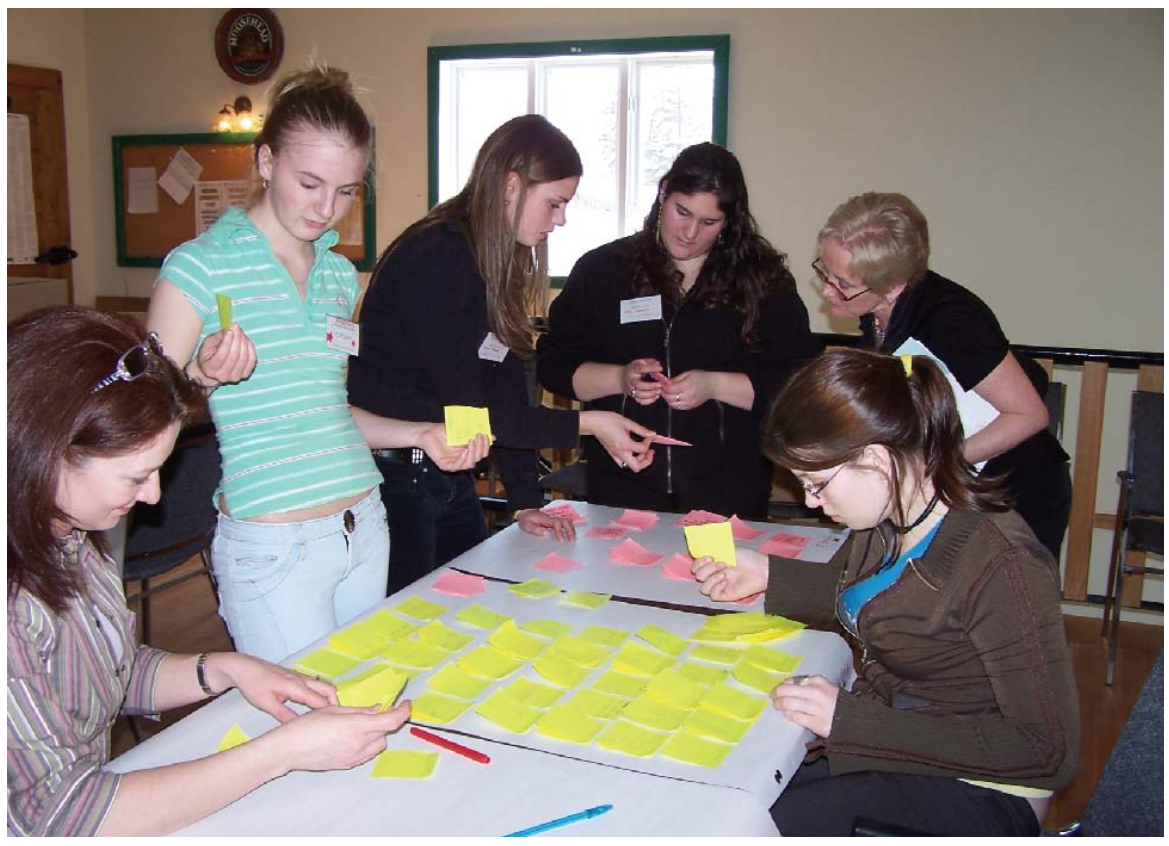

Fig. 3: Encouraging our students

\section{Summary of the Key Messages}

We recognized the richness of the feedback we received from the students, and thought that it is helpful to summarize some of the key messages our students sent to the adults who control our school system:

- It is extremely important to accept and encourage our students' role in creating the conditions for their success.

- Students need to be given ownership and to be engaged.

- Teachers have a profound responsibility, for they have the greatest impact on our students' educational experience and ultimate success.

\section{Moving Forward}

It was not long before we recognized that this first day with our students was just a beginning. It is not enough to take student feedback and assume that their voices have been heard. Giving our students a voice is not only about "listening," but 
also about empowering them. This notion led to a significant shift in the nature of the Student Focus Days to come.

Over the past two years we have held three subsequent Students Focus Days. SFD II was based on the realization that it was not enough to allow our students to "tell" us what they wanted, but that they had to "lead" the change in the context of their schools and centres. This meant that they had to translate their feedback into priorities and outcomes they could work towards with the support of the student body and adults within the schools.

Recognizing that there would be a number of significant challenges for students returning to their schools and centres to implement their plans, SFD III focused on providing them with enablers to carry out the work. These included the help of an adult and a small amount of financial support. The day was spent preparing to implement their plans with the support of these enablers.

At SFD IV, the students came ready to share the stories of their implementation, using aids that ranged from hand-drawn posters and collages to PowerPoint ${ }^{\circledR}$ presentations. Their use of language, ease in front of peers and adults, and ability to summarize the experience were astounding. However, the most powerful part of each presentation was the level of empathy, compassion, and benevolence that was a significant part of each and every plan. Our students showed their capacity to act both locally and globally, with results ranging from enabling extracurricular activities to "growing" their funds to support the development of wells in third world countries.

We had no idea when we began to "listen" to our students that first Student Focus Day that this experience would evolve into a part of the School Board culture. We have learned that sharing leadership with students involves risks that make some educational leaders uncomfortable. We know our students will challenge our accepted practices and bring to the conversations unique and innovative ideas that shake the foundations of these practices. However, our hope is that we will continue to have the courage to tap into the wealth of ideas and energy that our students bring to shared leadership. 


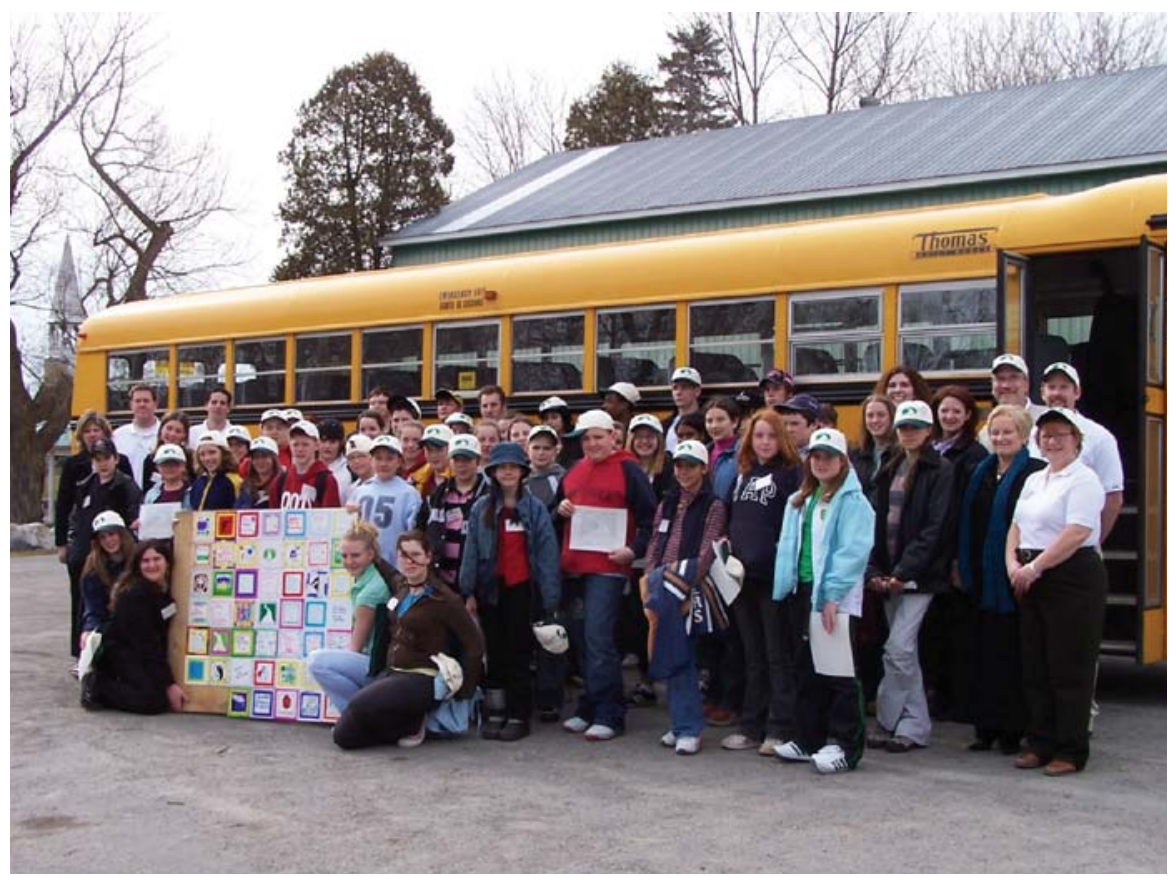

Fig. 4: Shared leadership

\section{Notes}

1. The New Frontiers School Board offers quality educational services to approximately 5,000 English youth and adult students in the Southwest region of Quebec, Canada. Its territory stretches from the St. Lawrence River to the North, Autoroute 15 to the East, the American border to the South, and the Ontario border to the West. The School Board has a total of fourteen schools and centres in rural and suburban areas, including two adult and professional education centres, two secondary schools, and ten elementary schools.

2. "Director General" is the term used for the chief executive officer of a Quebec school board; elsewhere in North America this position is most commonly called "Superintendent" or "Director of Education."

3. Professional conversation refers to conversations between and amongst professionals that are as free as possible from competition for resources; conversations that open one's experiences and opinions and those of colleagues to questioning, testing, and play in the hope of generating new possibilities (Robertson, 2002, p. 49). 
4. A "Governing Board" is the school or centre governance body, as mandated with the Quebec Education Act, which guides school orientations through such things as the Education Project, policy, and input into Success Plans. Governing Boards include a majority of parents, students at the secondary and adult levels, staff representation, and community representation. The Principal or Centre Director acts as a resource to the Governing Board.

5. Over the three-year period the Vice-Principals changed as some became Principals and new educational leaders joined the team, including: Suzan Fournier, Mike Helm, Daryl Ness, Lauren Small, Irene Agosto, Marc Brindle, and Jo-Anne Daviau.

6. While the School Board does not have separate middle schools, each of the secondary schools has developed a "middle-school program."

7. The Quebec Education Plan uses the Constructivist Approach as the cornerstone of curriculum change. This approach places students at the centre of their education, giving them control of their own learning. By using a project-based approach and carefully analyzing students' understanding, teachers are able to address their students' various learning styles and needs, while exploring the curriculum and various subject areas.

\section{References}

DuFour, R. \& Eaker, R. (1998). Professional Learning Communities at Work: Best Practices for Enhancing Student Achievement. Bloomington, IN: National Educational Service.

DuFour, R. \& Eaker, R. (May 2004). What is a "professional learning community"? Educational Leadership, 61(8), 6-11.

Newman, F.M. (1992). Student engagement and achievement in American secondary schools. New York: Teachers College Press.
Robertson, J. Kenneth (2002). Possibilities for educational leadership: The hermeneutics of superintendent-principal conversations. Unpublished dissertation. Edmonton, $\mathrm{AB}$ : University of Alberta.

Voke, Heather (2002, February). Student engagement: Motivating students to learn. Infobrief 28. Alexandria, VA: Association for Supervision and Curriculum Development. 


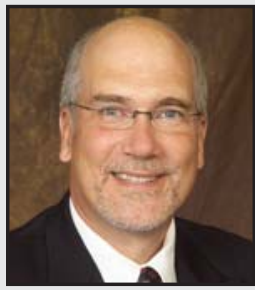

J. Kenneth Robertson, B.Ed., M.A., Ed.D., was the Director General of the New Frontiers School Board from July 2002 to September 2007, and is now the Director General of Champlain Regional College. He is an Adjunct Professor in University Centre for Educational Leadership at McGill University and a member of the Quebec Superior Council on Education. He spent six years in Western Canada, as a Regional Director for Alberta Education and Superintendent of Schools.

LINK TO:

http://www.csnewfrontiers.qc.ca/anglais/intro_en.htm 